\title{
Comparative Analysis of Performance of Two Scheffler Solar Concentrators Having Different Concentration Ratios
}

\author{
Prof. Anita Nene ${ }^{\# 1}$, Prof Dr. S. Suyambazhahan* ${ }^{2}$, Prof Dr S. Ramchandra ${ }^{\# 3}$ \\ ${ }^{\#}$ Mechanical department, Sathyabama University, Jeppiaar Nagar Chennai India. \\ 1 anita.nene@mitpune.edu.in \\ 3 aishram2006@gmail.com \\ * College of Engineering, Qassim University, Buraydah, KSA \\ ${ }^{2}$ suyamiitm@gmail.com
}

\begin{abstract}
Two different Scheffler concentrators with concentration ratio 48 and 17 were installed and experimentation was carried out to improve the performance of the Scheffler solar concentrator system. Receiver is the heart of the system. Parameters used for experimentation are related to receiver only. Shape of receiver, position of receiver, inlet temperature of water of receiver, covering of receiver with glass to reduce convection losses. Concentration ratio is the ratio of aperture area to receiver area both Scheffler concentrators have receiver of same size and volume. scheffler with concentration ratio 48 generates steam up to 3 bar gauge pressure of steam and heat gain rate is $2 \mathrm{kw}$, and scheffler with concentration ratio 17 develops up to 1 bar gauge pressure of steam and heat gain rate is $0.6 \mathrm{kw}$. If temperature of water at inlet is $\mathbf{5 0}$ degree instead of $\mathbf{3 0}$ degree, performance of Schefflers improves due to reduction in thermal inertia. Conical receiver due to more surface area for heat transfer during tilt gives better performance than cylindrical receiver to generate steam. As solar radiations increases efficiency of Scheffler solar concentrators decreases. If wind speed increases from 1 to $3 \mathrm{~m} / \mathrm{s}$ efficiency decreases.
\end{abstract}

Keywords-scheffler concentrator, solar radiations, thermal efficiency, concentration ratio, optimization, receiver.

\section{Introduction}

Fixed focus elliptical dish which is often called as Scheffler concentrator was introduced by the Wolfgang Scheffler, a German scientist in 1990[4]. The performance of Scheffler concentrator system depends on various thermal and optical properties of receiver, receiver geometry and orientation of the system with respect to sun position in sky[5]..

The literature survey shows that the types of receivers investigated both experimentally and numerically are mainly cavity receiver of cylindrical shape [9-14]. In some cases cavity receiver of conical, cone-cylindrical and hetro-conical in shape are also tested. Rupesh J. Patil [6], performed an experimental analysis on 8 $\mathrm{m}^{2}$ Scheffler reflector for water heating. Output power and efficiency of the system was $1.30 \mathrm{~kW}$ and $21.61 \%$ respectively at average value of beam radiation $742 \mathrm{~W} / \mathrm{m}^{2}$. Vishal R. Dafle [7], has done design, fabrication, and performance evaluation for $16 \mathrm{~m}^{2}$ Scheffler reflector for cooking application. The efficiency achieved was 37.41 $\%$. Rakesh Sharma [9], has developed and implemented a test procedure for paraboloid concentrating collector with cavity receiver on field unit. Performance equation was developed. Parametric study for performance improvement of Scheffler concentrator is not available in literature.

\section{Scheffler Concentrator System}

A Design of experimental setup, selection of Parameters such as (1) shape of receiver (2) initial heating of inlet temperature to $50^{\circ} \mathrm{C}$ (3) tilting of the receiver with horizontal at 30,45,60 degree (4) receiver with glass cover, were considered. Thermal analysis experimentally and analytically has been done with the objective of Optimization. The concentrator or reflector is the part of the system that directs radiation on to the receiver .It consists of a large number of glass plates. It is a small lateral section of a much larger parabola. A receiver is the element of the system where the radiation is absorbed and converted to some other energy form. Receiver which contains working fluid is placed at the focus of Scheffler concentrator. Receiver material is mild steel and surfaces are black painted having absorptivity 0.91. Delta Polyurethane, known as PUF material of $50 \mathrm{~mm}$ thickness is used for insulation for receiver surface except frontal surface. The aperture of the concentrator is the opening through which solar radiation enters the concentrator. Aperture area for big Scheffler is $6.5 \mathrm{~m}^{2}$ and for small Scheffler $2.5 \mathrm{~m}^{2}$ Concentration ratio is the ratio of aperture area to receiver area. The concerned concentrator is fixed focus which means sunlight is focused on a fixed point whereby the adjustment is designed in such a way that the burning point remains fixed. Daily rotation axis of concentrator is parallel to earth axis in north south direction. The focus is located on the axis of rotation to prevent it from moving when the 
concentrator rotates. During the day the concentrated light will only rotate around its own centre but not move sideways in any direction so focus is fixed

\section{Experimental Set Up}

Fig.1 and Fig.2 shows the experimental setups of Scheffler concentrator systems[8]. with area $2.7 \mathrm{~m}^{2}$ and $9.2 \mathrm{~m}^{2}$ and concentration ratio 17 and 48 respectively, cylindrical and conical receivers are used for experimentation. Diameter and volume of both the receivers are designed equal.

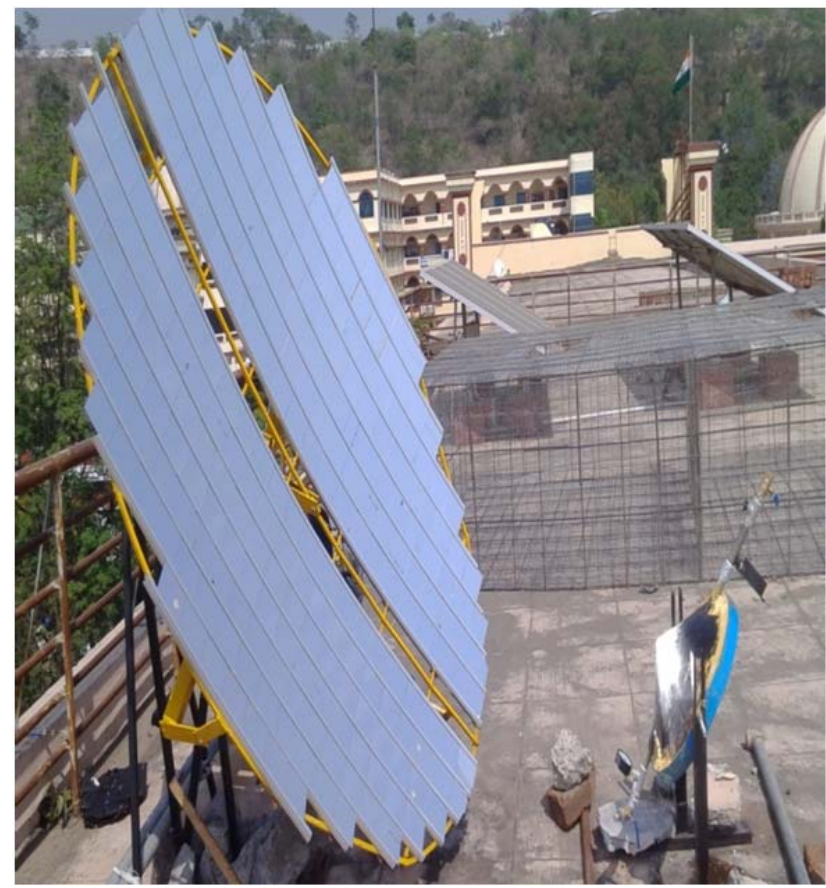

Fig.1. Experimental setups ( tilt condition) of small Scheffler, concentration ratio 17 with conical receive
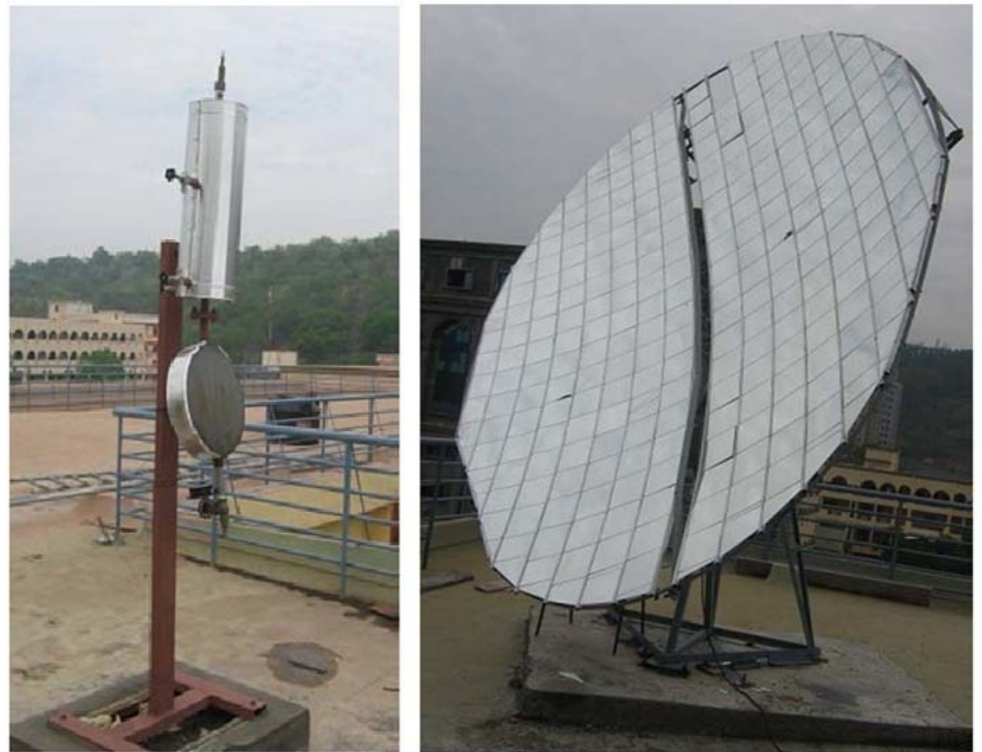

Fig.2. Experimental setup (Normal condition) of big Scheffler, concentration ratio 48 with cylindrical receiver

An anemometer is used to measure wind speed and ambient temperature is measured by temperature sensor. All instruments such as pyrometer, anemometer and temperature sensor are coupled with data logger. Data logger with its various instruments is mounted at weather station available at experimental field. The data logger is a microchip equipped tool that helps in measuring analogue data collected by the instruments and presents and stores them in digital format. K-type thermocouples are used for measuring the surface temperature of receiver. Tilting arrangement is provided for both receivers and measurement of titling angle has been done using an inclinometer. 
For big Scheffler, receiver and storage tank are built separately, while for small Scheffler, receiver cum storage tank is used. Experimentation is done as per Bureau of Indian Standards (BIS) procedure[1-3]. For both big and small Scheffler, working fluid is water. Mass flow rate of steam is measured and thermal Efficiency is calculated. Readings include focus Temperature, receiver surface temperature, Air temperature, Global radiation, Diffused radiation, wind speed, mass of steam generated per hour and pressure. More than fifty readings were recorded during month of March to May 2016 for different cases.

Thermal efficiency of receiver is calculated on the basis of parameters like(1) shapes of receiver(2) initial heating of inlet temperature to $50^{\circ} \mathrm{C}(3)$ tilting of the receiver with horizontal at 30,45,60 degree and(4) receiver with glass cover.

The thermal efficiency experimentally is calculated with equation:

Thermal efficiency $(\eta)=\frac{M_{S} \times h_{f g}}{A_{p} \times I_{b n} \times T} \times 100$

Where, $\mathrm{M}_{\mathrm{s}}$ - Mass flow rate of Steam $(\mathrm{kg} / \mathrm{hr}), \mathrm{h}_{\mathrm{fg}}-$ latent heat $(\mathrm{kJ} / \mathrm{kg})$

$\mathrm{I}_{\mathrm{bn}}-$ Direct Solar Radiation $\left(\mathrm{W} / \mathrm{m}^{2}\right), \mathrm{A}_{\mathrm{p}}$-aperture area

$\mathrm{T}-3600 / 1000$ (conversion factor)

\section{Result and Discussion}

In the present study parametric analysis has been done for improvement in thermal Efficiency of Scheffler concentrator systems used for steam generation. For small Scheffler steam generation rate is $0.5 \mathrm{~kg} / \mathrm{hr}$ at $1 \mathrm{bar}$ gauge steam pressure and $1.5 \mathrm{~kg} / \mathrm{hr}$ at 3 bar gauge steam pressure at normal condition. For big Scheffler steam generation rate is $1.5 \mathrm{~kg} / \mathrm{h}$ at 1 bar gauge steam pressure and $3.5 \mathrm{~kg} / \mathrm{hr}$ at 3 bar gauge steam pressure at normal condition. Table 1 shows values of thermal efficiency for different conditions of two Scheffler concentrators by experimentation.

TABLE I. Range of thermal efficiencies for different conditions (experimentally calculated).

\begin{tabular}{|c|c|c|c|}
\hline & \multirow[t]{2}{*}{ Condition } & \multicolumn{2}{|c|}{ Thermal Efficiency (\%) } \\
\hline & & $\begin{array}{c}\text { Low CR (17) p-up } \\
\text { to } 3 \text { bar absolute }\end{array}$ & $\begin{array}{c}\text { High CR (48) p-up to5 } \\
\text { bar absolute }\end{array}$ \\
\hline \multirow{4}{*}{ 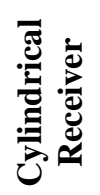 } & Normal Condition & 35 to 45 & 38 to 48 \\
\hline & Initial Heating & 54 to 58 & 48 to 52 \\
\hline & Tilting of Receiver & 28 to 30 & 30 to 32 \\
\hline & Receiver with Glass Cover & 28 to 35 & 35 to 38 \\
\hline \multirow{4}{*}{ 苞 } & Normal Condition & 30 to 32 & 30 to 35 \\
\hline & Initial Heating & 48 to 52 & 45 to 55 \\
\hline & Tilting of Receiver & 55 to 58 & 55 to 60 \\
\hline & Receiver covered with Glass cover & 20 to 30 & 33 to 38 \\
\hline
\end{tabular}

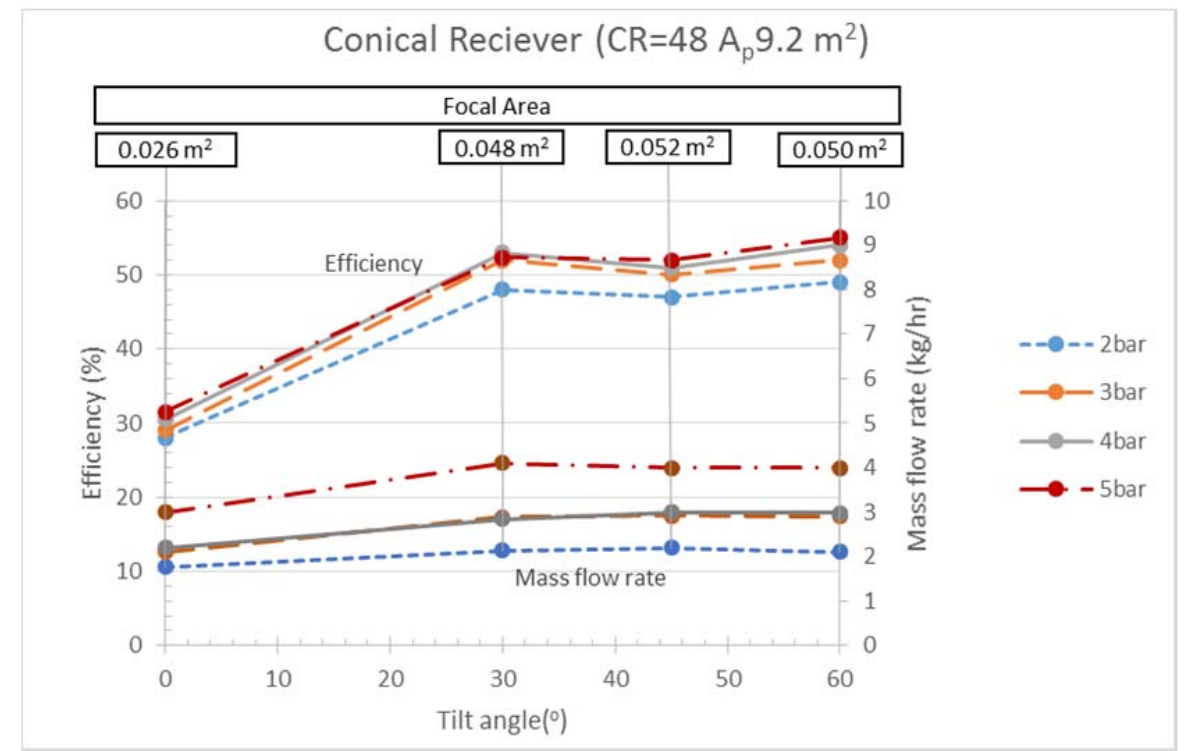

Fig 3. Efficiency and mass flow rates variation for different tilt angle of conical receiver for $9.2 \mathrm{~m}^{2}$ Scheffler concentrator. 


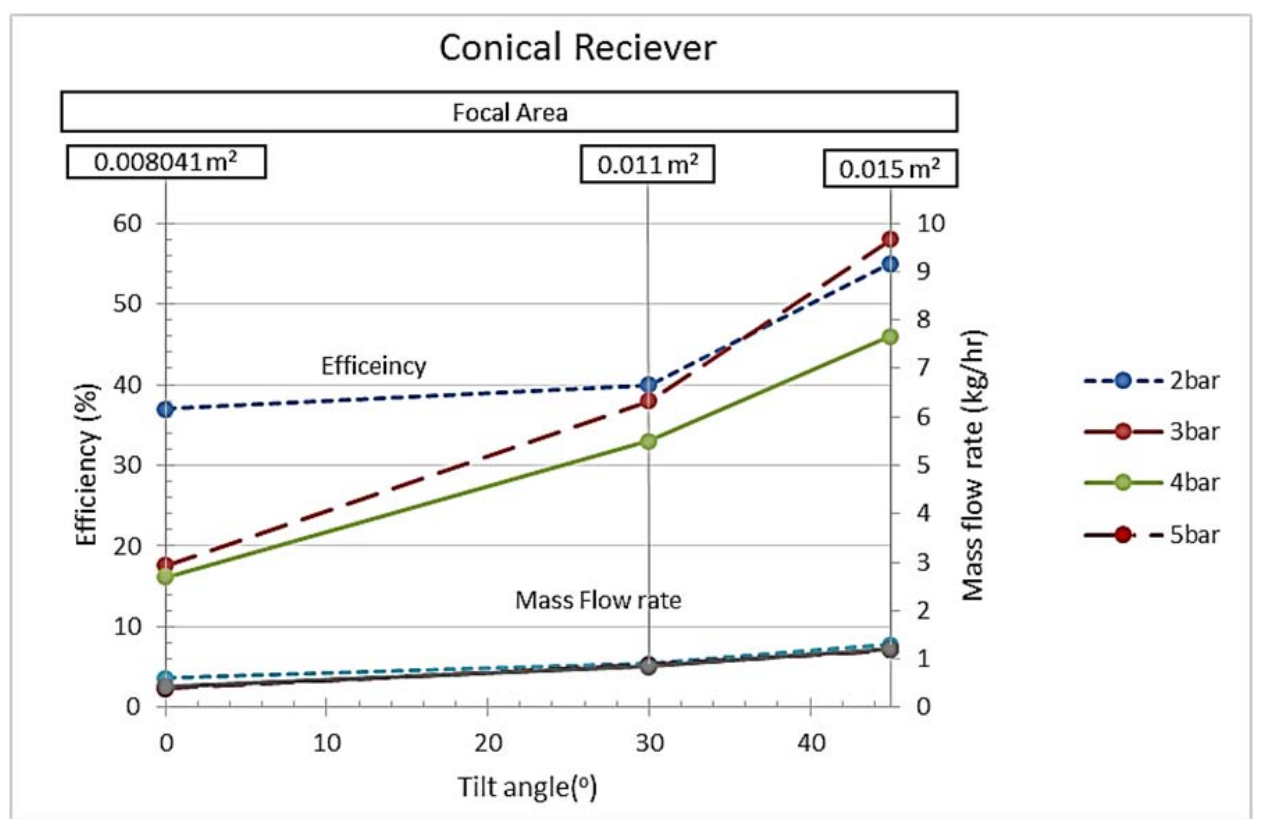

Fig. 4 Efficiency and mass flow rates variation for different tilt angle of conical receiver for $2.7 \mathrm{~m}^{2}$ Sheffler concentrator.

\section{A. Conical Receiver}

Fig. 3 and Fig.4 shows thermal efficiencies and mass flow rate during tilt of receiver in upward direction to horizontal, For big scheffler and small scheffler respectively. For conical receiver system efficiency and mass flow rate increases with tilt angle up to $45^{\circ}$ tilt of receiver with horizontal for small Scheffler. Tilt up to 60 degree it is out of focus for small scheffler. For big Scheffler mass flow rate and efficiency seems to increase up to $30^{\circ}$ and saturate beyond $30^{\circ}$ tilt of conical receiver. Tilt up to 60 degree is out of focus for big scheffler. Focal area were measured for all these conditions on receiver surface. At $45^{0}$ tilt area is $0.015 \mathrm{~m}^{2}$ for small scheffler. It shows for big scheffler that focal area on receiver surface does not increase significantly beyond $30^{\circ}$ tilt of receiver and focal area at 30 degree tilt is $0.042 \mathrm{~m}^{2}$

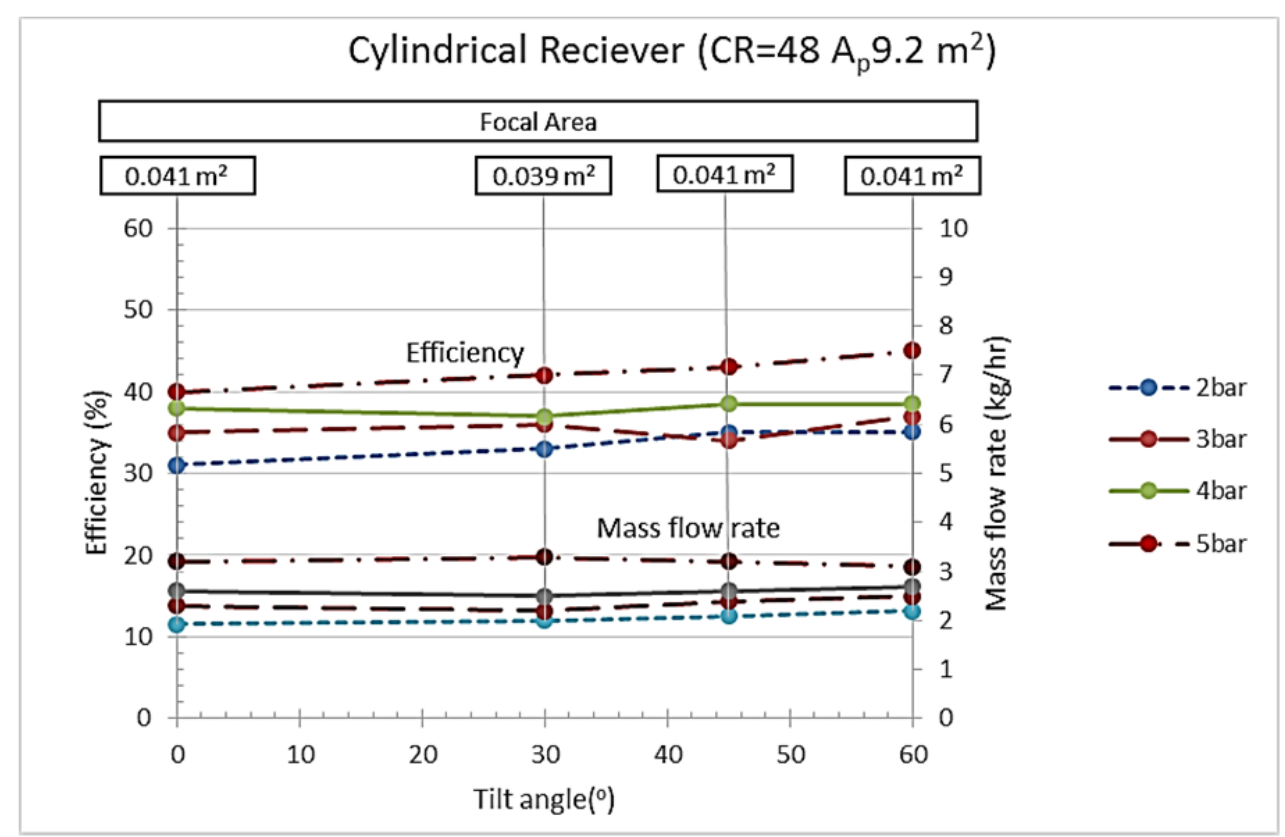

Fig. 5 Efficiency and mass flow rates variation for different tilt angle of cylindrical receiver for $9.2 \mathrm{~m}^{2}$ Sheffler Concentra 


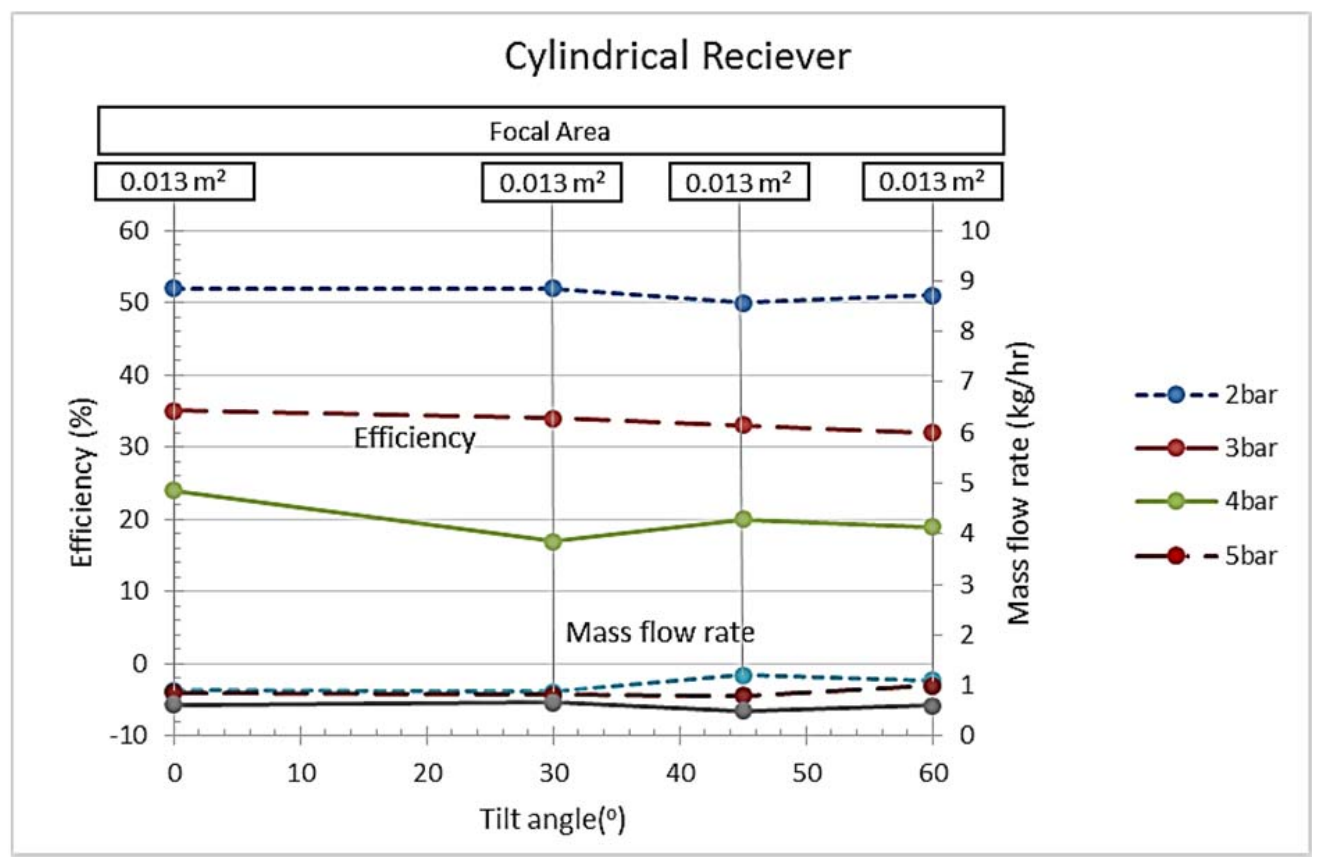

Fig. 6 Efficiency and mass flow rates variation for different tilt angle of cylindrical receiver for $2.7 \mathrm{~m}^{2}$ Sheffler concentrator

\section{B. Cylindrical Receiver}

For small and big Scheffler Concentrator tilting of cylindrical receiver with horizontal has very little increasing effect on efficiency and generated mass flow rate of steam as shown in fig.5\& fig. 6 . Focal area where solar rays get concentrated remains approximately same for tilt and without tilt conditions of cylindrical receiver. Hence it is not a good option for thermal efficiency improvement. Increase in steam pressure leads to increased efficiency and mass flow rate in big Scheffler concentrator while small Scheffler concentrator shows decrease in efficiency and mass flow rate with increase steam pressure above 2 bar gauge in both cases of conical and cylindrical receiver. Initial heating is the best option for cylindrical receiver. Tilting up to 30 degree for big scheffler and tilting up to $45^{\circ}$ for small scheffler with initial heating of inlet water of receiver up to 50 degree is best option for conical receiver.

\section{Conclusion}

An experimental results shows that cylindrical receiver has maximum efficiency in case of initial heating of water $\left(50^{\circ} \mathrm{C}\right)$ for small and big scheffler, as initial heating of inlet water reduces the thermal inertia and this result in increase in mass flow rate of steam, hence thermal efficiency gets improved. Conical receiver gives maximum efficiency for tilt of receiver $45^{\circ}$ for small Scheffler because in tilting condition it has maximum focus area $\left(0.015 \mathrm{~m}^{2}\right)$ which increase the heat input to the water .Conical receiver gives maximum efficiency For tilt of conical receiver $30^{\circ}$ for big scheffler.. Among different parameter tested, general condition and initial heating is found good operating condition for cylindrical receiver. Conical receiver performed well for initial heating and tilting condition. Thermal efficiency does not improve for glass cover condition. There is good agreement between analytical and experimental value of thermal efficiency with maximum deviation $20 \%$ for cylindrical receiver and $14 \%$ for conical receiver.

\section{References}

[1] John A.duffie and William A. Beckman, Solar Engineering of Thermal Processes, $3^{\text {rd }}$ Edition, John Willey and Sons, Inc, 2006.

[2] S.P.Sukhatme, J.K.Nayak, Solar Energy Principle of Thermal Collection and Storage, $3^{\text {rd }}$ edition, McGraw Hill Education (India) Pvt.Ltd., 2013.

[3] Yunus A.Cengel, Heat and Mass Transfer, $4^{\text {th }}$ edition, Tata McGraw Hill, 2013.

[4] Wolfgang Scheffler, "Introduction to the Revolutionary Design of Scheffler Reflectors", International Conference on Solar Cookers, Granada, Spain, 2006.

[5] C. A. Kinjavdekar, V. P. Muley, S. B. Kedare and J. K. Nayak, "A Test Procedure for Determining Optical Characteristics of a Dish Concentrator and its Implementation on a Scheffler Dish", Solar Energy Society of India, vol. 20, No. 1 \& 2, June - December, 2010.

[6] Rupesh J. Patil, Gajanan K. Awari, Mahendra P. Singh, “ Experimental Analysis Of Scheffler Reflector Water Heater”, Thermal Science, vol. 15, No. 3, pp. 599-604, 2011.

[7] Vishal R. Dafle, Prof. N.N.Shinde, " Design, Development \& Performance Evaluation Of Concentrating Monoaxial Scheffler Technology For Water Heating And Low Temperature Industrial Steam Application”, International Journal of Engineering Research and Applications (IJERA), vol. 2, Issue 6, pp.848-852, November- December 2012.

[8] Ajay Chandak, Sunil K. Somani, Deepak Dubey, “ Design, Development and Testing of Multieffect Distiller/Evaporator Using Scheffler Solar Concentrators", Journal of Engineering Science and Technology, vol. 4, No. 3, pp. 315 - 321, 2009.

[9] V.Rakesh Sharma, S.J.Bhosale, S.B.Kedare and J.K.Nayak, "Field Tests of the performance of parabolid solar concentrator ARUN160 at Latur", Advances in Energy Research, 2006. 
[10] M. Prakash, S.B. Kedare, J.K. Nayak, "Investigations on heat losses from a solar cavity receiver", Solar Energy, vol.83, pp. 157-170, 2008.

[11] M. Prakash, "Numerical Study of Natural Convection Heat Loss from Cylindrical Solar Cavity Receivers", ISRN Renewable Energy, Article ID 104686, 2014.

[12] Milind S Patil, "Heat Loss Characterization from Solar Concentrator Receiver- A Review", International Journal of Engineering Science and Technology, vol. 2, pp. 7531-7539, 2010.

[13] R. D. Jilte, S. B. Kedare, and J. K. Nayak, "Comparison of Cavity Receivers with and without Mouth-Blockage of Different Shapes and Sizes Used in Paraboloid Dish Applications", Journal of Fundamentals of Renewable Energy and Applications, vol. 2, Article ID R120306, 2012.

[14] B. S. Gawali, A. G. Kawade, G. S. Deshpande, "Thermal analysis of Scheffler cavity receiver for distribution and heat losses during solar period ”, ISHMT-ASME, Heat and Mass Transfer Conference January 4-6, Mumbai, India, 2010 .

\section{Author Profile}

Prof (Mrs) Anita Arvind Nene, Associate Professor, MAEER's MIT, Pune. Research scholar at Sathyabama University. Total teaching experience of 20 years in Mechanical Engineering

Prof Dr. S. Suyambazhahan, College of Engineering, Qassim University, Buraydah, KSA. Specialisation in Heat Transfer \& CFD, Teaching experience Total 28 years.

Prof. Dr. S Ramchandran Prof sathyabama University. Teaching experience 29 years in Mechanical Engineering. 